\title{
Retraction notice for: "Kaempferol suppresses human gastric cancer SNU-216 cell proliferation, promotes cell autophagy, but has no influence on cell apoptosis" [Braz J Med Biol Res (2019) 52(2): e7843]
}

\author{
Fan Zhang ${ }^{1}{ }^{1}$ and Cuimei Ma ${ }^{2}{ }^{2}$ \\ ${ }^{1}$ Teaching and Research Department of Diagnostics, Jining Medical University, Jining, China \\ ${ }^{2}$ Department of Gastroenterology, Affiliated Hospital of Jining Medical University, Jining, China
}

Retraction for: Braz J Med Biol Res | doi: 10.1590/1414-431X20187843 | PMID: 30785478 | PMCID: PMC6376319

The Brazilian Journal of Medical and Biological Research received a request from the authors to withdraw this manuscript. Meanwhile, the Editors became aware of a denouncement published by independent journalists from the "For Better Science" website including this paper. This denouncement consisted of potential data falsification and/or inaccuracy of results in western blots and flow cytometry plots.

As per consensus between the Authors and the Editors-in-Chief of the Brazilian Journal of Medical and Biological Research (BJMBR), the article titled "Kaempferol suppresses human gastric cancer SNU-216 cell proliferation, promotes cell autophagy, but has no influence on cell apoptosis" that was published in year 2019, volume 52, issue 2, (Epub Feb 14, 2019) has been retracted. 


\title{
Kaempferol suppresses human gastric cancer SNU- 216 cell proliferation, promotes cell autophagy but has no influence on cell apopu sis
}

\author{
Fan Zhang $\oplus^{1}$, Mu Cuim Ma $\mathbb{1}^{2}$ \\ ${ }^{1}$ Teaching and Research Department of Diagnostics, Jining Medica - viversit Jining, China \\ ${ }^{2}$ Department of Gastroenterology, Affiliated Hospital of Jining Mt ᄀ \. J. Jining, China
}

\begin{abstract}
Gastric cancer remains a serious threat to human health worldwide. Kaempferol a pl t-derived flavonoid compound with a wide range of pharmacological activities. This study aimed to investigate the efic on gastric cancer SNU-216 cell proliferation, apoptosis, and autophagy, as well as underlying potential mechanls Viability, proliferation, and apoptosis of SNU-216 cells after kaempferol treatment were evaluated using cell countir + 8 assay btomo-2'-deoxyuridine incorporation assay, and annexin V-FITC/PI staining, respectively. Quantitative reverse ans a PCR was performed to measure the mRNA expressions of cyclin D1 and microRNA-181a (miR-181a) in SNU-216 . Cell transfection was used to down-regulate the expression of miR-181a. The protein expression levels of cyclin D1, bcl- 2 ax, caspase 3, caspase 9, autophagy-related gene 7, microtubule-associated protein 1 light chain 3-I (LC3-I), I Beclin 1, ,62, mitogen-activated protein kinase (MAPK), extracellular regulated protein kinases (ERK), and phosphatid nosit kinase (PI3K) in SNU-216 cells were detected using western blotting. Results showed that kaempferol significa suppre ed SNU-216 cell viability and proliferation but had no influence on cell apoptosis. Further results sugges $d$ tha aer ierol significantly induced SNU-216 cell autophagy. The expression of miR-181a in SNU-216 cells after k? npfe MAPK/ERK and PI3K pathways in SNU-216 cells. op sion of miR-181a significantly reversed the kaempferol-induced MAPK/ERK and PI3K pathways inactivation in NU- ce'. This research demonstrated that kaempferol suppressed proliferation and promoted autophagy of hum rastric cor SNU-216 cells by up-regulating miR-181a and inactivating MAPK/ERK and PI3K pathways.

Key words: Gastric cancer; Kaempfero' vicroRNA-181a; Cell proliferation; Cell autophagy

\section{Introduction}

Gastric cancer is a majo ta. urden worldwide, which accounts for roughly $28,0, w$ cases and 10,960 deaths per year $(1,2$ ccor $g$ to the results of epidemiology resear, mi nle fa tors contribute to the occurrence of gastric habits and life yle, t, robacter pylori infection, and chronic stom in sease $(, 4)$. Although diagnosis and treatment of gastric cer have improved in recent years, the 5-ye survival rate of patients remains only $30 \%$ (5). The la of ective early diagnostic biomarkers and the side efte of semic therapies are major reasons for d (.. 6,7) . erefore, searching for novel and more

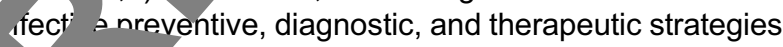
astric cancer are still extremely needed.

nt-derived medicines in cancer therapy have gaine more attention around the world, due to their safety, efficiency, and minimal side effects (8). Kaempferol

is a natural flavonoid compound found in many vegetables and fruits with a wide range of pharmacological activities $(9,10)$. Regarding its anti-cancer effects, several preliminary studies demonstrated that kaempferol suppressed the growth of multiple cancers, including breast cancer (11), lung cancer (12), colon cancer (13), bladder cancer (14), hepatic cancer (15), pancreatic cancer (16), and gastric cancer (17). For gastric cancer, Song et al. (17) demonstrated that kaempferol suppressed the proliferation of human gastric cancer MKN28 and SGC7901 cells, as well as the growth of tumor xenografts, by inactivating phosphatidylinositol 3 kinase/protein kinase 3 (PI3K/AKT) and mitogen-activated protein kinase/extracellular regulated protein kinases (MAPK/ERK) signaling pathways. More experimental research is still needed to further explore the specific molecular mechanisms of kaempferol on gastric cancer cells.
\end{abstract}


MicroRNAs (miRNAs) are small non-coding regulatory RNAs in eukaryotic cells, which can serve as gene regulators capable of controlling expression of multiple genes by targeting the $3^{\prime}$ untranslated regions ( $\left.3^{\prime} U T R\right)$ of the mRNAs (18). Kaempferol can exert anti-cancer effects by regulating miRNAs expressions in cancer cells (19). Previous experimental study showed that miRNA-181a (miR-181a) was down-regulated in gastric cancer tissues and played critical roles in suppressing gastric cancer HGC-27 cell proliferation, invasion, and metastasis (20). However, there is no information available about the effects of kaempferol on miR-181a expression in gastric cancer cells.

Thus, in this research, we assessed the proliferation, apoptosis, and autophagy of human gastric cancer SNU-216 cells after kaempferol treatment. Moreover, we analyzed the role of miR-181a in kaempferol-induced inactivation of MAPK/ERK and PI3K pathways in SNU216 cells. These findings will provide new evidence for further understanding the anti-cancer effects of kaempferol on gastric cancer.

\section{Material and Methods}

\section{Cell culture and treatment}

Human gastric cancer cell line SNU-216 was pro ed by Korean Cell Line Bank (Korea). Human gastric e neli GES-1 cells were purchased from Beijing In titu. or Cancer Research (China). SNU-216 and $c$ S-1 Cu were both cultured in Dulbecco's modified E jh medium (DMEM, Sigma-Aldrich, USA) supplemented w. 10\% fetal bovine serum (FBS, Gibco, Life $T$ mologies, $\checkmark S A$ ), $1 \%$ penicillin-streptomycin (Gibco, ife $\mathrm{Tec}$ nologies), and $1 \mathrm{mM} \mathrm{L-glutamine} \mathrm{(Sigma-Aldrich,} \mathrm{SA).} \mathrm{C} \mathrm{ures} \mathrm{were}$ maintained in a humidified incuhator (The. sher Scientific, USA) at $37^{\circ} \mathrm{C}$ with $5 \% \mathrm{CC}$

Kaempferol powder was ob in trom Sigma-Aldrich (catalog number: K013? sulfoxide (DMSO, Trmo Fishe Scientific) to a final storage concentratio $f$ according to the manufacturer's instry on. um-free DMEM was used to dilute kaempf solution $10-100 \mu \mathrm{M}$ before experiments. The cremic tructure of kaempferol is displayed in Figure

Cell vía. ase

vià + was measured using cell counting kit-8 CK Beyorme Biotechnology, China) assay. Briefly, $\checkmark c, 16$ cells were seeded in a 96-well plate (C. ᄀr, Corning Incorporated, USA) with $1 \times 10^{4}$ cells per wu and exposure to $10-100 \mu \mathrm{M}$ kaempferol for 24 or $48 \mathrm{~h}$. Then, $10 \mu \mathrm{L}$ CCK-8 solution was added into each well of the plate followed by incubation for $1 \mathrm{~h}$ at $37^{\circ} \mathrm{C}$. After that, the absorbance of each well at $450 \mathrm{~nm}$ was recorded using a micro-plate reader (Bio-Tek Instruments, USA). Cell viability (\%) was quantified by average

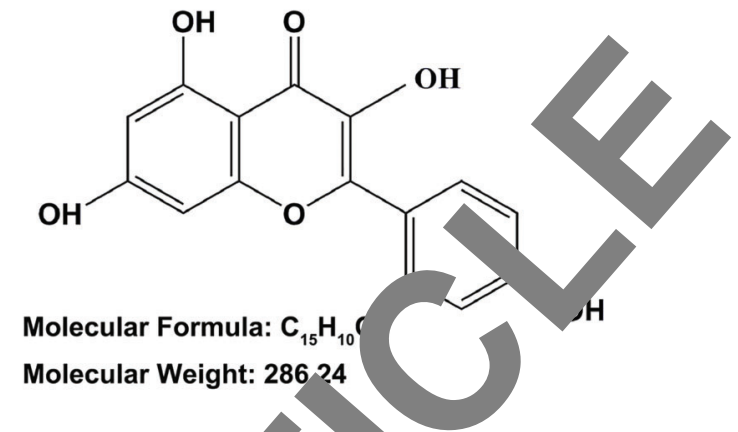

Figure 1. The chemical str' are o, empferol.

absorbance of kaemp, rol t. tment group/average absorbance of control gro $\times 100$

Cell prolifera $n$ ?

Cell prolifera was evaluated using 5-bromo-2'deoxyur (Brd ' ncorporation assay (Calbiochem, USA) ac rair the manufacturer's protocol. Briefly, SNU-216 were seeded in 6-well plates (Costar, Corning Inc orated) with $1 \times 10^{5}$ cells per well. BrdU $\mathrm{q} / \mathrm{mL}$ ) was added into each well of the plate before $50 \mu$. kaempferol treatment for $4 \mathrm{~h}$. Incubation time with kaemy erol was $24 \mathrm{~h}$. After that, cell proliferation (\%) of tr group was quantified by number of BrdU positive $(+$, cells/number of total cells $\times 100 \%$.

\section{Quantitative reverse transcription PCR (qRT-PCR)}

qRT-PCR was conducted to detect the expressions of cyclin D1 and miR-181a in SNU-216 cells after $50 \mu \mathrm{M}$ kaempferol treatment or miR-181a inhibitor transfection. Briefly, after relevant treatment or transfection, total RNAs in SNU-216 cells were isolated using TRIzol ${ }^{\mathrm{TM}}$ Plus RNA Purification kit (Invitrogen, USA). SuperScript ${ }^{\mathrm{TM}}$ III Platinum $^{\mathrm{TM}}$ One-Step qRT-PCR kit (Invitrogen) was used to detect the expressions of cyclin D1 and $\beta$-actin. MirVana $^{T M}$ qRT-PCR miRNA Detection kit (Invitrogen) was used to detect the expression of miR-181a and U6; $\beta$-actin and $\mathrm{U} 6$ acted as endogenous control, respectively. The primers were cyclin D1: 5'-CCCTCGGTGTCCTACTT CAAA-3' (forward) and 5'-CACСТCСТССТССТССТСТ TC-3' (reverse); $\beta$-actin: 5'-CCAGGCACCAGGGCGT GATG-3' (forward) and 5'-CGGCCAGCCAGGTCCAGA CG-3' (reverse); miR-181a: 5'-GAACATTCAACGCTGTC GGTG-3'; U6: 5'-TGCGGGTGCTCGCRRCGGCAGC-3'. Data was quantified using $2^{-\triangle \triangle \mathrm{Ct}}$ method (21).

\section{Cell apoptosis assay}

Cell apoptosis was determined using annexin V-FITC/ $\mathrm{PI}$ apoptosis detection kit (Becton-Dickinson, USA) following the manufacturer's instructions. SNU-216 cells were seeded in a 6-well plate (Costar, Corning Incorporated) with $1 \times 10^{5}$ cells per well and exposure to $50 \mu \mathrm{M}$ kaempferol for $24 \mathrm{~h}$. Then, cells in each well were harvested, washed twice with phosphate buffered saline (PBS, Beyotime 
Biotechnology), and stained with annexin V-FITC/PI solution for $25 \mathrm{~min}$ at $37^{\circ} \mathrm{C}$ in the dark. FACScan flow cytometry (BD Biosciences, USA) was performed to analyze cell apoptosis. Data were quantified using FlowJo software (FlowJo LLC, USA) (22).

\section{Cell transfection}

miR-181a inhibitor and negative control (NC) were both designed and synthesized by GenePharma Corporation (China). The sequence for miR-181a inhibitor was: 5'-ACUCACCGACAGCGUUGAAUGUU-3'. Cell transfection was conducted using Lipofectamine 3000 reagent
(Invitrogen) in line with the manufacturer's protocol. Transfection efficiency was evaluated using qRT $\mathrm{CR}$.

\section{Western blotting}

After $50 \mu \mathrm{M}$ kaempferol treatment and/or $\mathrm{h}$ inhibitor transfection, total proteins in SNU-216 cells ere isolated using RIPA lysis and extractio. uffer (7) iermo Fisher Scientific, USA) and quanti usin $C O$. protein assay kit (Beyotime Biotechnolo ). Bio-Rad L.S-Tris Gel system (Bio-Rad Laboratories, ( A) was sed to establish the western blotting sy $n$. n steins in equal concentrations were ele op. sea in polyacrylamide

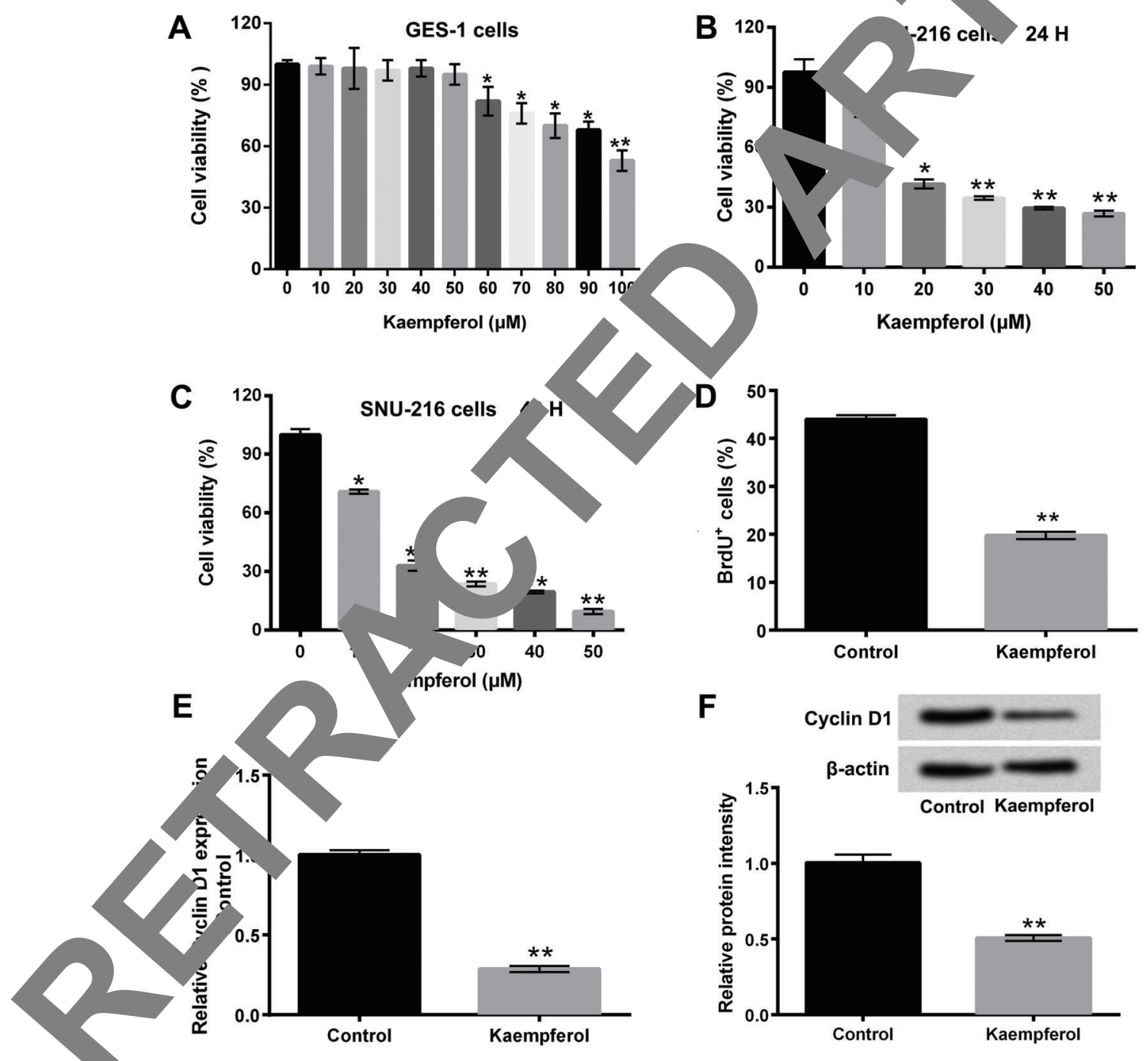

Figure 2. Kaempferol suppressed SNU-216 cell viability and proliferation. A, Viability of GES-1 cells after $10-100 \mu \mathrm{M}$ kaempferol treatment was detected using cell counting kit-8 assay. $B$ and $C$, Viability of SNU-216 cells after 10-50 $\mu \mathrm{M}$ kaempferol treatment for 24 and $48 \mathrm{~h}$ were measured using CCK-8 assay. D, Proliferation of SNU-216 cells after $50 \mu \mathrm{M}$ kaempferol treatment was evaluated using 5-bromo-2'-deoxyuridine incorporation assay (BrdU). $E$ and $F$, mRNA and protein expression levels of cyclin D1 in SNU-216 cells after $50 \mu \mathrm{M}$ kaempferol treatment were determined using quantitative reverse transcription PCR and western blotting, respectively. Data are reported as means $\pm S D$. ${ }^{*} \mathrm{P}<0.05,{ }^{* *} \mathrm{P}<0.01$ (ANOVA or $t$-test). 
gels and transferred onto nitrocellulose membranes (Millipore, USA), which were incubated with primary antibodies. All primary antibodies were prepared in $1 \%$ bovine serum albumin (BSA, Beyotime Biotechnology) solution at a dilution of 1:1000. Anti-cyclin D1 antibody (\#2922), anti-Bcl-2 antibody (\#2872), anti-Bax antibody (\#2774), anti-pro-caspase 3 antibody (\#9662), anti-cleavedcaspase 3 antibody (\#9664), anti-pro-caspase 9 antibody (\#9502), anti-cleaved-caspase 9 antibody (\#9505), antiautophagy-related gene 7 (ATG7) antibody (\#2631), antimicrotubule-associated protein 1 light chain 3-I/II (LC3-I/ II) antibody (\#4108), anti-beclin 1 antibody (\#3738), antip62 antibody (\#8025), anti-MAPK antibody (\#9212), antip-MAPK antibody (\#9216), anti-ERK antibody (\#9102), anti-p-ERK antibody (\#5726), anti-PI3K antibody (\#4292), anti-p-PI3K antibody (\#4228), and anti- $\beta$-actin antibody (\#4970) were all purchased from Cell Signaling Technology (USA). Subsequently, the nitrocellulose membranes were incubated with anti-mouse (rabbit) $\operatorname{lgG}(\mathrm{H}+\mathrm{L})$ DYLight $^{\mathrm{TM}}$ 680 conjugate (\#5470, \#5366, Cell Signaling Technology) for $1 \mathrm{~h}$ at room temperature. Odyssey System (Licor Biosciences, Germany) was used to record signals of proteins. Data were quantified using Quantity One software (Bio-Rad Laboratories) (23).

\section{Statistical analysis}

All experiments were repeated at least three mer GraphPad 6.0 software (GraphPad, USA) was us or statistical analysis. Data are reported as $r$ ans \pm Statistical comparisons were made using o th $t$-tes or one-way analysis of variance (ANOVA). $\mathrm{P}<0$. was considered statistically significant.

\section{Results}

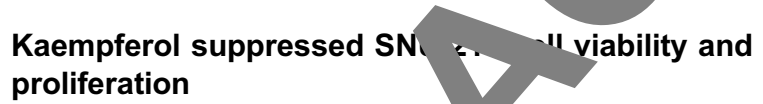

Firstly, we detected viab of GES-1 cells after 10-100 $\mu \mathrm{M}$ kaempf $\mathrm{s}$ tr tmen using CCK-8 assay. Results in Figure 2, 10 10 -50 $\mu \mathrm{M}$ kaempferol treatment had n signit t effect on GES-1 cell viability, while 60-100 kaemp, rol treatment inhibited the viability of $G E S-1$ olls $(P<0.05$ or $P<0.01)$. These results $\mathrm{s}^{\prime}$ gested tha igh concentrations of kaempferol (over $5 \mu \mathrm{M}$ ' night have toxic effects on human normal gastric the ability of SNU-216 cells after 10-50 $\mu \mathrm{M}$ $\mathrm{k}$ ? ero gure $\mathrm{ZB}$ and show that kaempferol inhibited the viability cells in a dose- and time-dependent manner (P 05 or $\mathrm{P}<0.01$ ). Kaempferol treatment at $50 \mu \mathrm{M}$ for $24 \mathrm{~h}$. educed the viability of SNU-216 cells to 26.87 $\pm 3.18 \%$ and $50 \mu \mathrm{M}$ kaempferol treatment for $48 \mathrm{~h}$ reduced the viability of SNU-216 cells to $9.63 \pm 4.28 \%$. Considering that $50 \mu \mathrm{M}$ kaempferol treatment for $24 \mathrm{~h}$ was able to significantly inhibit the viability of SNU-216 cells, this protocol was chosen for subsequent experiments.
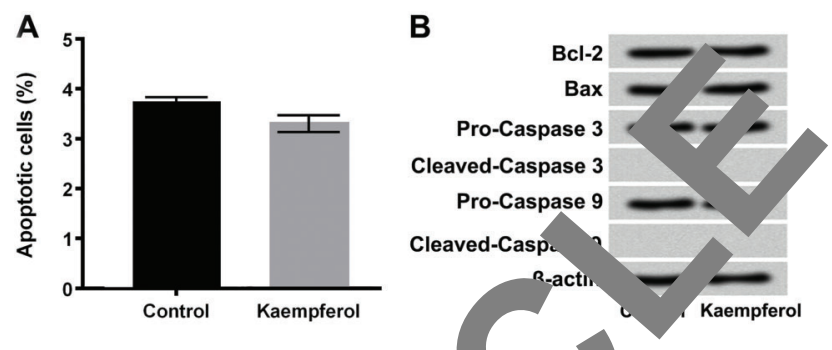

Figure 3. Kaempferol had no in ence C SNU-216 cell apoptosis. A, Annexin V-FITC talı used to assess the apoptosis of SNU-216 ce afte. $\mu \mathrm{M}$ kaempferol treatment. $B$, Western blotting was $r$ ormed to tect the expressions of Bcl-2, Bax, pro-caspas o, ved-caspase 3, pro-caspase 9, and cleaved-caspase 9 in SNU. cells after $50 \mu \mathrm{M}$ kaempferol treatment. Data ar, ted as mıans \pm SD ( $t$-test).

Figure 2 icnlays compared to the control group, the rate Bro sitive $(+)$ cells in $50 \mu \mathrm{M}$ kaempferol treatment ap was significantly reduced $(P<0.01)$. In addition, RT-PCR and western blotting illustrated the mRIA and protein expression levels of cyclin D1 I. NU-216 cells were both decreased after $50 \mu \mathrm{M}$ kaem erol treatment (Figure $2 \mathrm{E}$ and $\mathrm{F}, \mathrm{P}<0.01$ ). The results indicated that appropriate concentration of kat.npferol could suppress gastric cancer SNU-216 cell ability and proliferation, but had no significant effect on normal gastric cells.

\section{Kaempferol had no influence on SNU-216 cell apoptosis}

Annexin V-FITC/PI staining and western blotting were performed to assess SNU-216 cell apoptosis after $50 \mu \mathrm{M}$ kaempferol treatment for $24 \mathrm{~h}$. As displayed in Figure $3 \mathrm{~A}$, the rate of apoptotic cells was not changed after $50 \mu \mathrm{M}$ kaempferol treatment, compared to the control group. The expression levels of bcl-2, bax, pro-capsase 3 , cleavedcaspase 3, pro-caspase 9 , and cleaved-caspase 9 were also not changed in SNU-216 cells after $50 \mu \mathrm{M}$ kaempferol treatment, compared to the control group (Figure 3B). These findings suggested that kaempferol had no influence on SNU-216 cell apoptosis.

\section{Kaempferol induced SNU-216 cell autophagy}

To analyze the effects of kaempferol on SNU-216 cell autophagy, the protein expression levels of ATG7, LC3-I, LC3-II, beclin 1, and p62 in SNU-216 cells after $50 \mu \mathrm{M}$ kaempferol treatment were measured using western blotting. Figure $4 \mathrm{~A}$ and $\mathrm{B}$ show that $50 \mu \mathrm{M}$ kaempferol treatment significantly down-regulated the protein expression level of p62 $(P<0.01)$ and remarkably up-regulated the protein expression levels of ATG7, LC3-II/I, and beclin 1 in SNU-216 cells $(P<0.05$ or $P<0.01)$. These findings revealed that kaempferol obviously induced gastric cancer SNU-216 cell autophagy. 
A
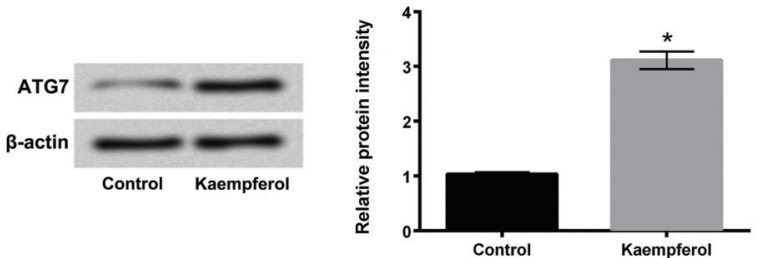

B
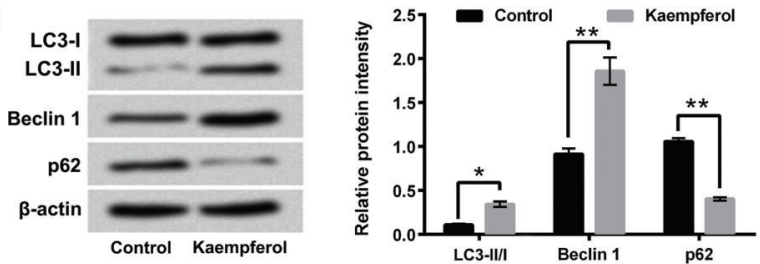

Figure 4. Kaempferol induced SNU-216 cell autophagy. After 50 $\mu \mathrm{M}$ kaempferol treatment, the protein expression levels of ATG7, LC3-I, LC3-II, beclin 1, and p62 in SNU-216 cells were evaluated using western blotting. ATG7: autophagy-related gene 7; LC3: microtubule-associated protein 1 light chain 3 . Data are reported as means $\pm \mathrm{SD}$. ${ }^{*} \mathrm{P}<0.05,{ }^{* \star} \mathrm{P}<0.01$ (t-test).
Kaempferol up-regulated the expression of miR-181a in SNU-216 cells

The expression level of miR-181a in SNI 16 olls after kaempferol treatment was detected no qRT PCR. Results in Figure 5 show that $50 \mu \mathrm{M}$ ka treatment significantly enhanced the expression le, of miR-181a in SNU-216 cells $(P<0.01)$. result aplied that miR-181a might participate in effe kaempferol on SNU-216 cell proliferatic inhibition, and autophagy occurrence.

\section{Kaempferol inactivated AP, $-\mathrm{RK}$ and PI3K} pathways in SNU-21f "/s

The activation of MA $=R K$ and PI3K in SNU-216 cells after kaemr ol treat. it was evaluated using western blottin As splayed in Figure 6, $50 \mu \mathrm{M}$ kaempferol treatme. si reduced the expression rates of $\mathrm{p}-\mathrm{MAPh}$ APK, $\mathrm{p}-\mathrm{ERK} / \mathrm{ERK}$, and $\mathrm{p}-\mathrm{PI} \mathrm{KK} / \mathrm{PI} \mathrm{KK}$ in SNU cells $(0.01)$. These findings indicated that kae fer ld inactivate MAPK/ERK and PI3K pathways astric cancer SNU-216 cells.

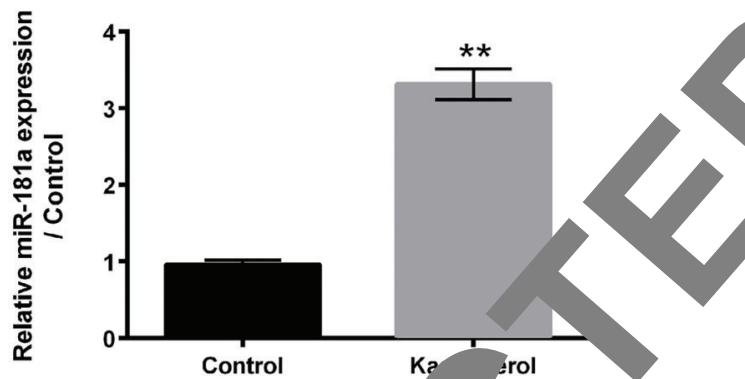

Figure 5. Kaempferol up-regulated the e ression microRNA (miR)-181a in SNU-216 cells. Quantitativ verse anscription PCR was conducted to determin the expre of miR-181a in SNU-216 cells after $50 \mu \mathrm{M} k$. treatment. Data are reported as means $\pm S D$. ${ }^{* *} \mathrm{P}<0.0$, te

\section{1a participated in the kaempferol-induced} MAt ERK and PI3K pathways inactivation in SNU$216 \mathrm{c}$ s.

$F$ ally, to verify the roles of miR-181a in kaempferolincuced MAPK/ERK and PI3K pathways inactivation, iR-181a inhibitor was transfected into SNU-216 cells. Results in Figure 7A illustrate that miR-181a inhibitor transfection significantly down-regulated the expression level of miR-181a in SNU-216 cells $(P<0.01)$. Figure 7B shows that miR-181a inhibitor transfection notably reversed the kaempferol-induced MAPK/ERK and PI3K pathways inactivation in SNU-216 cells by enhancing the expression rates of $\mathrm{p}-\mathrm{MAPK} / \mathrm{MAPK}$, $\mathrm{p}-\mathrm{ERK} / \mathrm{ERK}$ and $\mathrm{p}-\mathrm{PI} \mathrm{KK} / \mathrm{PI} \mathrm{KK}(\mathrm{P}<0.01)$. These findings suggested that miR-181a played critical roles in
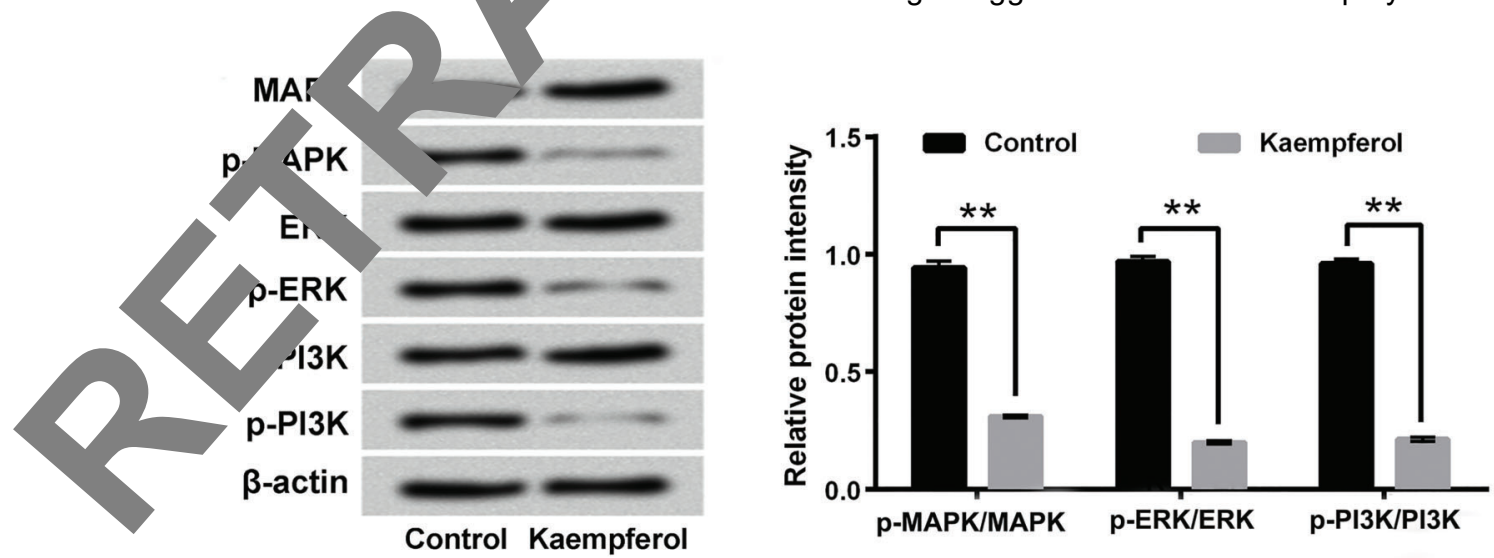

Figure 6. Kaempferol inactivated MAPK/ERK and PI3K pathways in SNU-216 cells. After $50 \mu \mathrm{M}$ kaempferol treatment, the expressions of MAPK, p-MAPK, ERK, p-ERK, PI3K, and p-PI3K in SNU-216 cells were determined using western blotting. MAPK: mitogen-activated protein kinase; ERK: extracellular regulated protein kinases; PI3K: phosphatidylinositol 3 kinase. Data are reported as means \pm SD. ${ }^{* *} \mathrm{P}<0.01$ ( $t$-test). 
A

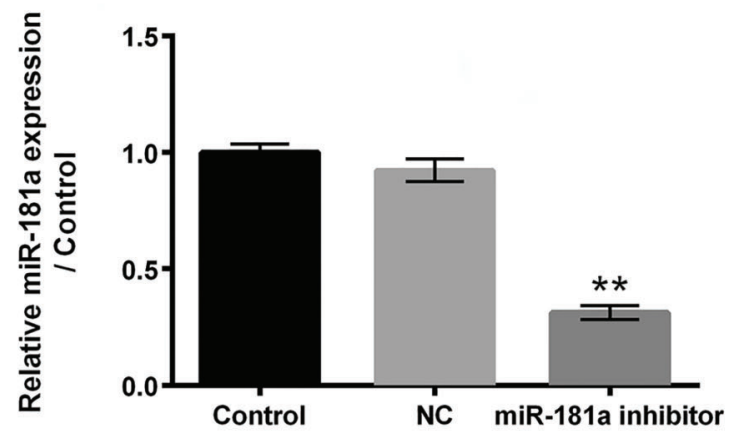

B

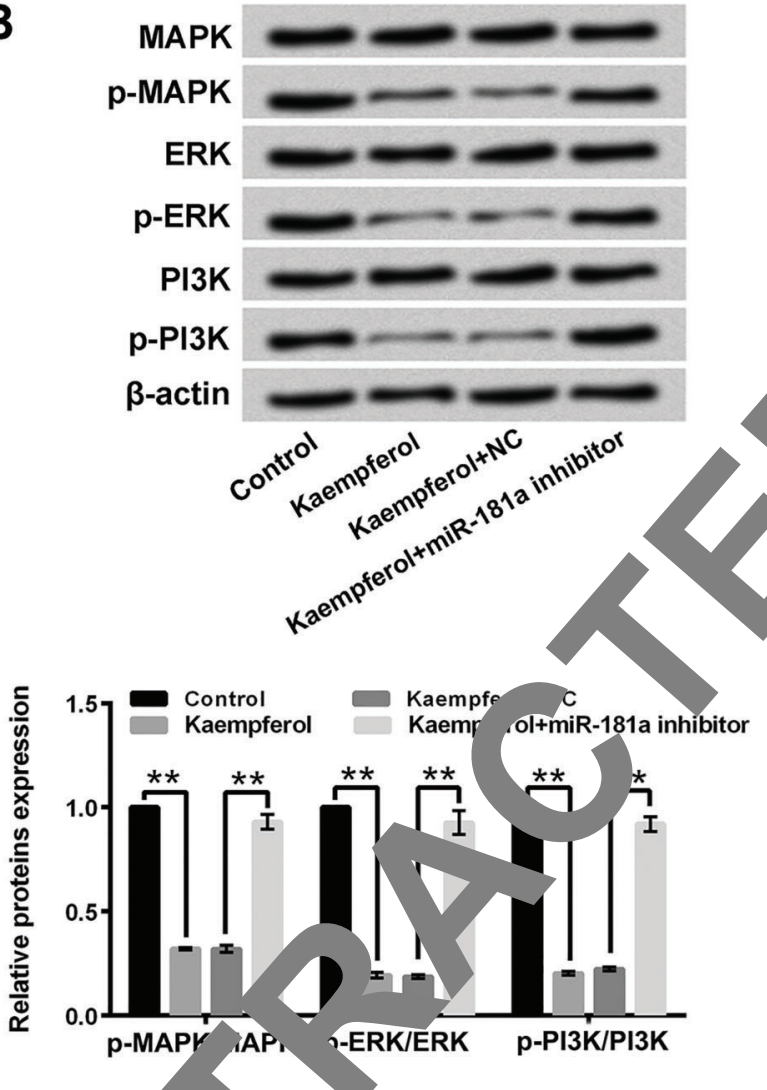

Figure 7. $\mathrm{mi}{ }_{\triangle} \hat{R}_{\mathrm{M}}(\mathrm{miR})-181 \mathrm{a}$ participated in the kaempferol-induce MAPK/L and PI3K pathways inactivation in SNU-216 ells $A$, After miR-181a inhibitor transfection, the expres $n$ of $\mathrm{R}$-181a in SNU-216 cells was detected using quantitat vers anscription PCR. $B$, Western blotting was pe ed ate the expressions of MAPK, p-MAPK, K, ERK, $\sigma \mathrm{K}$, and $\mathrm{p}-\mathrm{PI} 3 \mathrm{~K}$ in SNU-216 cells after $50 \mu \mathrm{M}$ ven eatment and/or miR-181a inhibitor transfection. $\Lambda$ egative control; MAPK: mitogen-activated protein kinase; ERh vtracellular regulated protein kinases; PI3K: phosphatidylinositol 3 kinase. Data are reported as means $\pm S D$. ${ }^{* *} \mathrm{P}<0.01$ (ANOVA)

kaempferol-induced MAPK/ERK and PI3K pathways inactivation in gastric cancer SNU-216 cells.

\section{Discussion}

As one of the most common gastrointestir tur ors, gastric cancer remains a serious threat to $h \mathrm{c}$. ealth worldwide $(1,24)$. In this research, we showed tha ferol, a plant-derived flavonoid compound, inhibited y uric cancer SNU-216 cell proliferation and in a cell tophagy. Moreover, kaempferol enh d th ression of miR-181a in SNU-216 cells. urthermore, miR-181a participated in the kaempferol duced lactivation of MAPK/ERK and PI3K path, 's INI 16 cells.

Plant-derived medicir sa made their own niche in the treatment of $\mathrm{m}$ ' $\mathrm{e}$ disec $\mathrm{s}$, including cancers $(25,26)$. An epidemic ogy dy demonstrated that there was a negative ociation etween occurrences of cancers and $c$ sur tion of foods containing kaempferol (27). In found that an appropriate concentration of mpferol could reduce gastric cancer SNU-21 viab, and proliferation, but had no influence in poptosis. The mRNA and protein expressiol els of cyclin D1, which plays pivotal roles in cancer o proliferation (28), were both decreased kaempferol treatment. Considering that kaempferol had . in found to exert anti-proliferative effects on gastric cance MKN28 and SGC7901 cells (17), the results of our ch further indicated that kaempferol could suppress múriple gastric cancer cell proliferation.

Cell autophagy has been considered as a nonapoptotic form of programmed cell death (29). Guo et al. (30) suggested that kaempferol induced hepatic cancer cell death through endoplasmic reticulum stress-CCAAT/ enhancer-binding protein homologous protein (CHOP)autophagy signaling pathway. Huang et al. (15) proved that kaempferol induced human hepatic cancer cell autophagy via adenosine $5^{\prime}$-monophosphate-associated protein kinase (AMPK) and AKT signaling pathways. Thus, in the present research, we also investigated the effects of kaempferol on gastric cancer SNU-216 cell autophagy. We found that the protein expression levels of ATG7, LC3-II/I, and beclin 1 were all enhanced and the protein expression level of p62 was decreased in SNU216 cells after kaempferol treatment. ATG7 is a core autophagy regulator and required for autophagy-dependent lipid metabolism (31). During autophagy, a cytosolic form of LC3 (LC3-I) is lapidated and converted to form LC3-II, which is a key process of autophagy pathway (32). Beclin 1 is a positive regulator of cell autophagy and p62 is a negative regulator of cell autophagy $(33,34)$. Therefore, we could conclude that kaempferol also played anticancer effects on gastric cancers by inducing gastric cancer cell autophagy.

Numerous studies demonstrated that miRNAs had critical roles in the regulation of multiple cellular processes and participated in the progression of many cancers (35). Many plant-derived medicines, including kaempferol, can 
exert anti-cancer effects by modulating the expressions of miRNAs $(19,36)$. In this research, we revealed that kaempferol enhanced the expression level of miR-181a in SNU-216 cells, suggesting that miR-181a might participate in the effects of kaempferol on gastric cancer cells. Moreover, this result was consistent with a previous study, which showed that miR-181a was down-regulated in gastric cancer tissues and played central roles in suppressing gastric cancer HGC-27 cell proliferation, invasion, and metastasis (20).

Song et al. (17) reported that kaempferol suppressed the proliferation of gastric cancer cells by inactivating PI3K/AKT and MAPK/ERK signaling pathways. Consistent with this previous study, we also found that kaempferol could inactivate MAPK/ERK and PI3K pathways in gastric cancer SNU-216 cells. Moreover, suppression of miR-181a reversed the kaempferol-induced MAPK/ERK and PI3K pathways inactivation in SNU-216 cells. These findings suggested that miR-181a participated in the kaf pferolinduced inactivation of MAPK/ERK and PI3K $p$, Iwa in gastric cancer SNU-216 cells. Considering tha IP ERK and $\mathrm{PI}$ K pathways played critical roles in promotiı. ras' cancer cell proliferation and autophagy $(27,38)$, the in dils of our research implied that kaempferol s 'resse' jastric cancer cell growth by up-regulating 181c ractivating MAPK/ERK and PI3K pathwe s.

In conclusion, our research d nonstra $d$ that kaempferol suppressed proliferatio. nd $\mathrm{mo} d$ autophagy of human gastric cancer $\mathrm{U}-\mathrm{z}$ cells by up-regulating miR-181a and inactiv MAPh RK and PI3K pathways. This study wili de $h$ ful for further understanding the anti-cancer $e^{e^{r}}+s$ of ka pferol on gastric cancer and provide a cort cal basis for deeply exploring the treatment of $g$ ric jy kaempferol.

\section{References}

1. Siegel RL, Miller KD, Jemal A. Cancer Statistics, 2017. CA Cancer J Clin 2017; 67: 7-30, doi: 10.3322/caac.21387.

2. Wadhwa R, Taketa T, Sudo K, Blum MA, Ajani JA. Modern oncological approaches to gastric adenocarcinoma. Gastro enterol Clin North Am 2013; 42: 359-369, doi: 10.1016/ j.gtc.2013.01.011.

3. Peille AL, Wong SS, Kiefer F, Zeitouni B, Maier A, Fo ault et al. Abstract LB-314: Whole exome sequencing an gastric cancers reveal two distinct genomic alter on pa. with implications in drug sensitivity. Can $R_{e}$ 314, doi: 10.1158/1538-7445.AM2014-LB-3.

4. Fu DG. Epigenetic alterations in gastri-ancer ( $\mathrm{h} w)$. Mol med rep 2015; 12: 3223-32? aoi: $10.3892 / \mathrm{mmr}$. 2015.3816.

5. Liu H, Gao Y, Song D, Liu T, Feng Correla n between microRNA-421 expression level and p. ols of gastric cancer. Int J Clin Exp Path o. 15128-15132, doi: 10.1007/s00104-013-2598-5.

6. Orditura M, Galizia G rza V, ambardella V, Fabozzi A, Laterza MM, et al ieá ent c gastric cancer. World $J$ Gastroenterol $20 \quad 20.20$. i7.1635.

7. Karakas E setzman on Sochaczewski C, Haist T, Pauthner onz D. Limitations of surgery for cancer of the uprar gastro, tinal tract. Chirurg 2014; 85: 186-191, doi: 1007/s00104,J13-2598-5.

8. $Y$ e $A, Y$, $X$, Wang $Y$, Wang $P$, Xiao Y. Antiproliferation ana higre $n$ induced by gypenosides in human colon nce, in' -0 and esophageal cancer Eca-109 cells. i nan E. Toxicol 2014; 33: 522-533, doi: 10.1177/0960 57771.

in F, Luo X, Tsun A, Li Z, Li D, Li B. Kaempferol enhances suppressive function of Treg cells by inhibiting FOXP3 phosphorylation. Int Immunopharmacol 2015; 28: 859-865, doi: 10.1016/j.intimp.2015.03.044.

10. Dhiman A, Nanda A, Ahmad S. A quest for staunch effects of flavonoids: Utopian protection against hepatic ailments. Arabian J Chem 2012; 12: 1702-1711, doi: 10.1016/j.arabjc. 2012.05.001.
11. Kim St iwang KA, Choi KC. Treatment with kaempferol suppress breast cancer cell growth caused by estrogen nd triclosan in cellular and xenograft breast cancer models.

Vutr Biochem 2016; 28: 70-82, doi: 10.1016/j.jnutbio. 5.09.027.

E, Park SJ, Choi YS, Jeon WK, Kim BC. Kaempferol suppresses transforming growth Factor-beta1-Induced Epithelial-to-Mesenchymal transition and migration of A549 lung cancer cells by inhibiting Akt1-Mediated Phosphorylation of Smad3 at Threonine-179. Neoplasia 2015; 17: 525537, doi: 10.1016/j.neo.2015.06.004.

13. Lee HS, Cho HJ, Kwon GT, Park JH. Kaempferol downregulates Insulin-like Growth Factor-I Receptor and ErbB3 Signaling in HT-29 human colon cancer cells. J Can Prev 2014; 9: 161-169, doi: 10.15430/JCP.2014.19.3.161.

14. Dang Q, Song W, Xu D, Ma Y, Li F, Zeng J, et al. Kaempferol suppresses bladder cancer tumor growth by inhibiting cell proliferation and inducing apoptosis. Mol Carcinog 2015; 54: 831-840, doi: $10.1002 / \mathrm{mc} .22154$.

15. Huang WW, Tsai SC, Peng SF, Lin MW, Chiang JH, Chiu YJ, et al. Kaempferol induces autophagy through AMPK and AKT signaling molecules and causes $\mathrm{G} 2 / \mathrm{M}$ arrest via downregulation of CDK1/cyclin B in SK-HEP-1 human hepatic cancer cells. Int J Oncol 2013; 42: 2069-2077, doi: 10.3892/ ijo.2013.1909.

16. Lee J, Kim JH. Kaempferol inhibits pancreatic cancer cell growth and migration through the blockade of EGFR-related pathway in vitro. PloS One 2016; 11: e0155264, doi: 10.1371/ journal.pone.0155264.

17. Song $\mathrm{H}$, Bao J, Wei $\mathrm{Y}$, Chen $\mathrm{Y}$, Mao $\mathrm{X}$, Li J, et al. Kaempferol inhibits gastric cancer tumor growth: An in vitro and in vivo study. Oncol Rep 2015; 33: 868-874, doi: 10.3892/or.2014.3662.

18. Costa FF. Non-coding RNAs: new players in eukaryotic biology. Gene 2015; 357: 83-94, doi: 10.1016/j.gene.2005.06.019.

19. Kim K, Kim S, Moh SH, Kang H. Kaempferol inhibits vascular smooth muscle cell migration by modulating BMPmediated miR-21 expression. Mol Cell Biochem 2015; 407: 143-149, doi: 10.1007/s11010-015-2464-5. 
20. Lin F, Li Y, Yan S, Liu S, Qian W, Shen D, et al. MicroRNA181a inhibits tumor proliferation, invasiveness, and metastasis and is downregulated in gastric cancer. Oncol Res 2015; 22: 75-84, doi: 10.3727/096504014X14024160459203.

21. Ish-Shalom S, Lichter A. Analysis of fungal gene expression by real time quantitative PCR. Methods Mol Biol 2010; 638: 103-114, doi: 10.1007/978-1-60761-611-5.

22. Xiao X, Zhou L, Cao P, Gong H, Zhang Y. MicroRNA-93 regulates cyclin $\mathrm{G} 2$ expression and plays an oncogenic role in laryngeal squamous cell carcinoma. Int J Oncol 2015; 46: 161-174, doi: 10.3892/ijo.2014.2704

23. Ansorena $E$, De Berdt $P$, Ucakar $B$, Simon-Yarza $T$, Jacobs $D$, Schakman $O$, et al. Injectable alginate hydrogel loaded with GDNF promotes functional recovery in a hemisection model of spinal cord injury. Int J Pharm 2013; 455: 148-158, doi: 10.1016/j.jpharm.2013.07.045.

24. Khatoon J, Rai RP, Prasad KN. Role of Helicobacter pylori in gastric cancer: Updates. World J Gastrointest Oncol 2016; 8: 147-158, doi: 10.4251/wjgo.v8.i2.147.

25. Pistollato F, Giampieri F, Battino M. The use of plant-derived bioactive compounds to target cancer stem cells and modulate tumor microenvironment. Food Chem Toxicol 2015; 75; 58-70, doi: 10.1016/j.fct.2014.11.004.

26. Saklani A, Kutty SK. Plant-derived compounds in clinical trials. Drug Discov Today 2008; 13: 161-171, doi: 10.1016/ j.drudis.2007.10.010.

27. Ozcan C, Yaman M. Determination of Kaempferol in Rosa canina, Urtica dioica, Terebinthina chica and Porty ce oleracea by HPLC-MS. Asian J Chem 2013; 25: 589762, doi: 10.14233/ajchem.2013.15311.

28. Qie S, Diehl JA. Cyclin D1, cancer progre jion, ad opportunities in cancer treatment. $J$ Mol N 2016; 1313-1326, doi: 10.1007/s00109-016-1475

29. Levine B, Yuan J. Autophagy in cell death: an ocent convict? J Clin Invest 2005; 115: 267 _.38, doi: 10.172/ $\mathrm{JCl} 26390$.

30. Guo H, Lin W, Zhang X, Zhang $\mathrm{Hu} \mathrm{Z,} \mathrm{L,} \mathrm{et} \mathrm{al.}$ Kaempferol induces hepatocellular cal ell death via endoplasmic reticulum stress-CHOP-autophagy signaling pathway. Oncotarget 2017; 8: 82207-82216, doi: 1 18632/ oncotarget.19200.

31. Juhasz G, Erdi B, Sass M, Neufeld TP. At der dent autophagy promotes neuronal health, stress tole e, a longevity but is dispensable for metamorphosis in , ophila. Genes Dev 2007; 21: 3061-30 doi: 10.1101 gad. 1600707.

32. Aparicio IM, Martin Munõz $P$ a fido C ena FJ, Tapia JA. The autophagy-re ed prot-in LC3 is processed in stallion spermatoz during hort-and longterm storage and the ate ful conditions. Animal 2016; 10: 1182 191, 10.1017/S175173111600 0240.

33. Toton E, Lisiak N, aW P, Rybczynska M. Beclin-1 and its role as a target for anticar therapy. J Physiol Pharmacol 2014; 65: $45^{\circ}$

34. Jiang $P, N$ ashir $L N$ LC3- and p62-based biochemical methods fo anlaryols of autophagy progression in mammalian ce. Methods 2015; 75: 13-18, doi: 10.1016/ j.ym 111.02 .

35. Tutar mif d cancer; computational and experimental approa . Curr Pharm Biotechnol 2014; 15: 429, doi: 10.2174, 8920101505140828161335.

Duggal J, Aarrison JS, Studzinski GP, Wang X. Involvement microRNA181a in differentiation and cell cycle arrest in iced by a plant-derived antioxidant carnosic acid and min $D$ analog doxercalciferol in human leukemia cells. MicroRNA 2012; 1: 26-33, doi: 10.2174/22115366112010 10026.

j7. Wei L, Li Y, Suo Z. TSPAN8 promotes gastric cancer growth and metastasis via ERK MAPK pathway. Int J Clin Exp Med 2015; 8: 8599-8607.

38. Xing $X$, Zhang $L$, Wen $X$, Wang $X$, Cheng $X$, Du $H$, et al. PP242 suppresses cell proliferation, metastasis, and angiogenesis of gastric cancer through inhibition of the PI3K/AKT/ mTOR pathway. Anticancer Drugs 2014; 25: 1129-1140, doi: 10.1097/CAD.0000000000000148. 